\title{
Performance Analysis of FTTH using GEPON in Direct and External Modulation
}

\author{
V. Khanaa ${ }^{1 *}$, Krishna Mohanta ${ }^{2}$ and T. Saravanan ${ }^{3}$ \\ 'Department of CSE, Sri Sai Ram Engg. College, Leo Nagar, Chennai-600044, India; \\ drvkannan62@yahoo.com \\ ²Department of ECE, Bharath University, Chennai-600073, India; krishnamohanta@gmail.com; \\ ${ }^{3}$ Professor \& Head, Department of ETC, Bharath University, Chennai-600073, India; saravanan.etc@bharathuniv.ac.in
}

\begin{abstract}
This work is intended to simulate an optical fiber communication system, FTTH with GEPON architecture, for both the direct and external modulation and to analyze the bit error rate (BER) at different distances.
\end{abstract}

Keywords: FTTH, PON, GEPON, Tripleplay Service, BER.

\section{Introduction}

With the advancement in the communication systems, there is a need for large bandwidth to send more data at higher speed. Residential subscribers demand high speed network for voice and media-rich services. Similarly, corporate subscribers demand broadband infrastructure so that they can extend their local-area networks to the internet backbone. This demands the networks of higher capacities at lower costs. Optical communication technology has developed rapidly to achieve larger transmission capacity and longer transmission distance. High data rates can be achieved if the data remain in the optical domain. The vision of Fiber-tothe-Home (FTTH) was developed to satisfy the perceived need for future consumer applications. Optical fiber would permit high bandwidth transport, remove "bottlenecks" as video-rich services are developed, enable upgrades, and permit passive multiplexing that would remove remote powering costs [1].

The steady increase in the demand for broadband services and the consequent increase in the volume of generated traffic in our communication networks have motivated the need to implement next generation networks. FTTH is the end game for many service providers. As compared to other broadband access technologies such as Digital Subscriber Line (DSL), and cable/modem, Passive Optical Network (PON) technology seems to be the best solution to alleviate the bandwidth bottleneck in the access network. From a historical perspective, the first bandwidth breakthrough in the access network was the arrival of DSL and cable based solutions. Because of the limited bandwidth of a coaxial cable, the complexity of the cable systems is expected to be higher than that of PONs. More users can be accommodated by applying different transmission techniques in the FTTH architecture. For deployment of access networks, operators are encouraged to invest on a PON infrastructure. Incorporating PON offers a good solution to increase the capacity of standard FTTH architectures. Although PON technology is mature for backbone networks, its user handling capacity and longer transmission distance is still considered for access networks. Therefore, there is still a need to solutions for PON in FTTH access networks [2].

\footnotetext{
* Corresponding author:

V. Khanaa (drvkannan62@yahoo.com)
} 


\section{FTTH using GEPON}

First part of the project is to simulate the FTTH using Gigabit Ethernet Passive Optical Network (GEPON). In this FTTH, network between the OLT and the ONUs is passive, meaning that it doesn't require any power supply. The presence of only passive elements in the network decreases its operational and maintenance costs. The blocks for the section is shown in Figure 1.

The schematic diagram consists of a data transmitter of $1.25 \mathrm{~Gb} / \mathrm{sec}$ and a video transmitter (Figure 2).

In the case of data transmitter, PRBS generator produced bit stream is directly fed to the NRZ electrical driver, the output of the electrical driver goes to the direct modulated laser for producing optical signal. For improving the BER the direct modulated laser is replaced with an external modulator driven by a continuous laser having the same wavelength. The modulated light is amplified by the EDFA [3].

In the case of video transmitter, there are two sine wave generator having different frequencies and goes to the input of the summer, then the summer mixes both the frequencies and finally goes to direct modulator and then to amplifier. The block diagram for the video trans mitter is shown in Figure 3. The outputs of both amplifiers are fed to multiplexer,both video and the voice/data combines and passes through the optical fiber. Now at the end of the

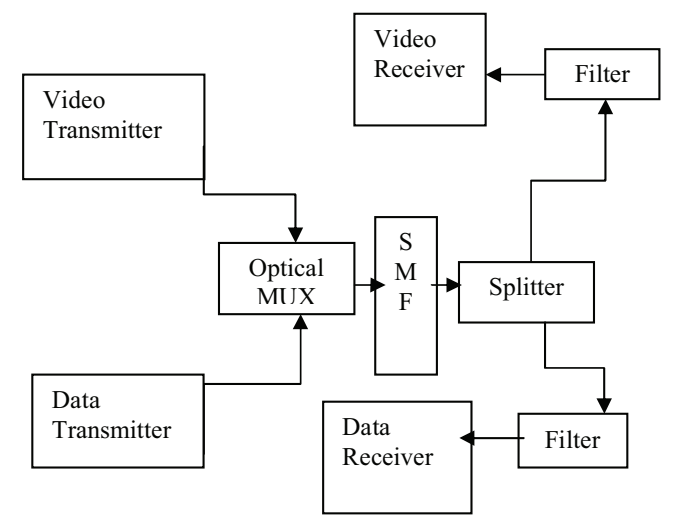

Figure 1. Block diagram of FTTH using GEPON.

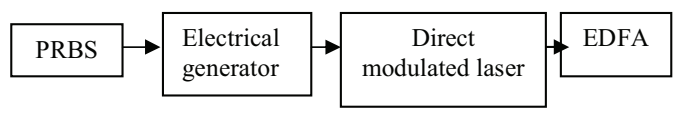

Figure 2. Block diagram of data transmitter.

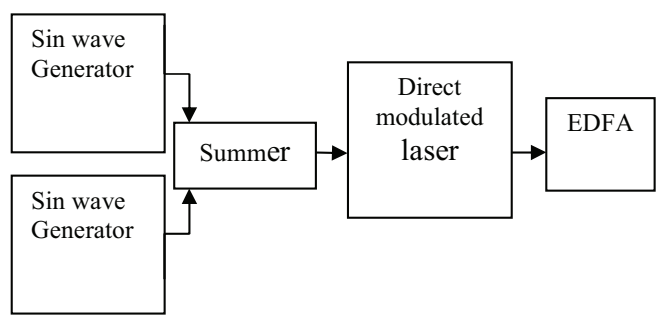

Figure 3. Block diagram of video transmitter.

receiver side, every ONU has a particular receiver for both the reception of the video and the voice/data. Before the reception, a splitter is used to differentiate the particular user. The optical signal from central office travels through fiber and arrives at optical network termination unit. At the subscriber, the optical signal demultiplexes into data/ voice and video components with the help of the optical filter. Then the data and video signal fed to corresponding detectors. Then both the sine waves are filtered out using electrical filter. Data/voice is transmitted at wavelength of $1490 \mathrm{~nm}$ and video at $1550 \mathrm{~nm}$. The data is transmitted at $1.25 \mathrm{~Gb} / \mathrm{s}[4]$.

\section{Simulation of FTTH Architecture}

The system setup of FTTH using GEPON architecture is simulated by Optsim 5.3. The simulation diagram consists of a PRBS generator which is producing $1.25 \mathrm{Gbits} / \mathrm{s}$ and is directly fed to the NRZ electrical driver. Then the output of the electrical driver goes to the direct modulated laser having a wavelength of $1490 \mathrm{~nm}$ and get amplified using EDFA. In the case of video there are two sine wave generators, having different frequencies of $55.2 \mathrm{MHz}$ and $547.2 \mathrm{MHz}$ and having phase shift of 90 degree. Then it goes to the input of the summer, and then summer mixes both the frequencies. It is fed to direct modulated laser of wavelength $1550 \mathrm{~nm}$. Then data and video is multiplexed and transmitted over single mode optical fiber of length 5 to $20 \mathrm{Km}$ [5].

The output of the optical fiber is fed to the input of the optical splitter which splits the input into the 1:8 outputs. The splitter is used to differentiate the particular user. It works as a balanced splitter with the same attenuation on each output. Attenuation is set to a default value $0 \mathrm{~dB}$, so this component implements an ideal splitter without any insertion loss, i.e. a component that perfectly splits the 
input signals. Then the outputs are fed to the corresponding receiver of each user. In the project, simulations are done by 1:8 splitters; it can be further expanded up to the $1: 16,1: 32$ depending upon the capacity of the users. At the transmitter side both the voice as well as data is in the form of the electrical signal, which is converted to the light signal with the help of the laser and it is combined. The optical filters separate the video and the data. To convert the data and video again in the original form, corresponding detectors are there. The same phenomenon is repeated or done simultaneously for different users at the same time. To measure the spectrum of the video and data, spectrum analyzer is used. The data is transmitted as light pulses over the fiber, but due to Inter symbol Interference (ISI) dispersion is produced. So in the effect of such things error should be occurred. So to measure the error, BER Tester is used. At the receiver side, every ONT has a particular detector for both the reception of the video and the data. APD photodiode is used as the detector [6-8]

By analyzing the FTTH using GEPON with direct modulation in the case of data, distortion is high as the distance increases. So in the data transmission section NRZ electrical generator is followed by an external modulator which is of mach-zender type. It is driven by a continuous laser source of wavelength 1490nm (Figure 4, 5, 6, 7).

\section{Results and Discussion}

By simulating the FTTH using the GEPON system, as already discussed it has separate channels for the voice and

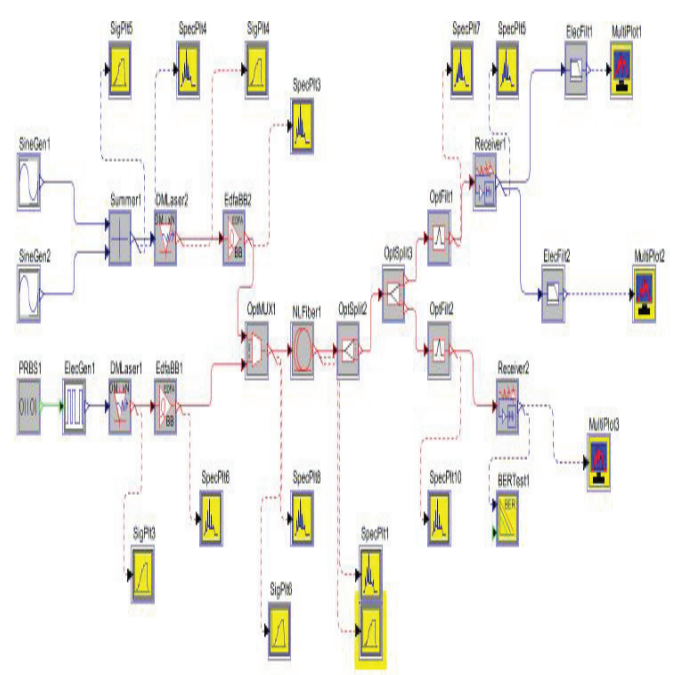

Figure 4. Simulation layout of FTTH using GEPON having single user in direct modulation using OptSim.

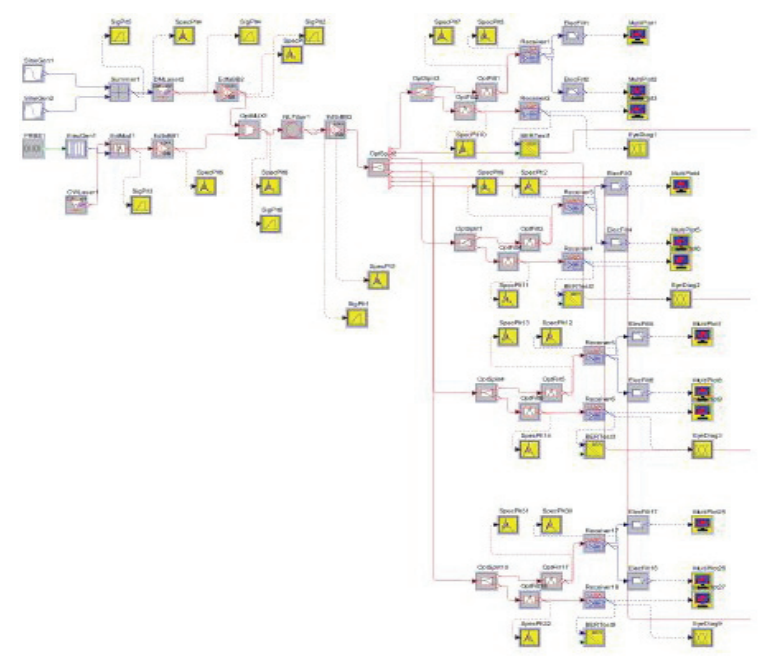

Figure 5. Simulation layout of FTTH using GEPON having 8 users with direct modulation

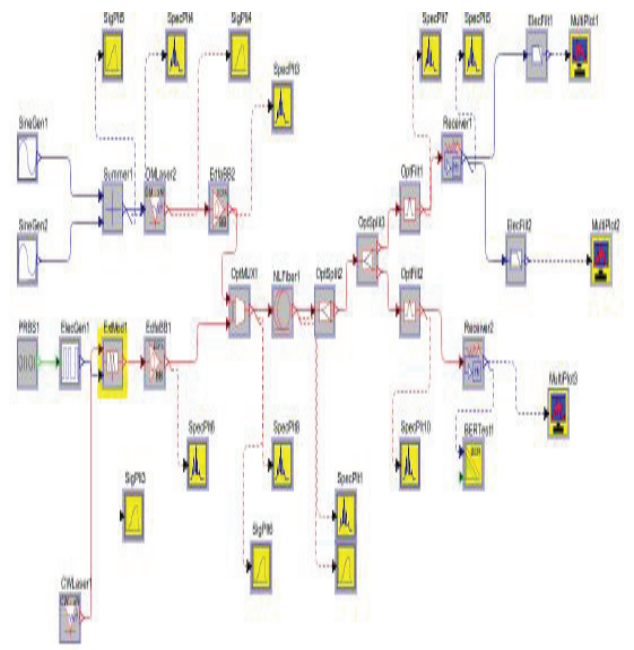

Figure 6. Simulation layout of FTTH using GEPON having single user in external modulation.

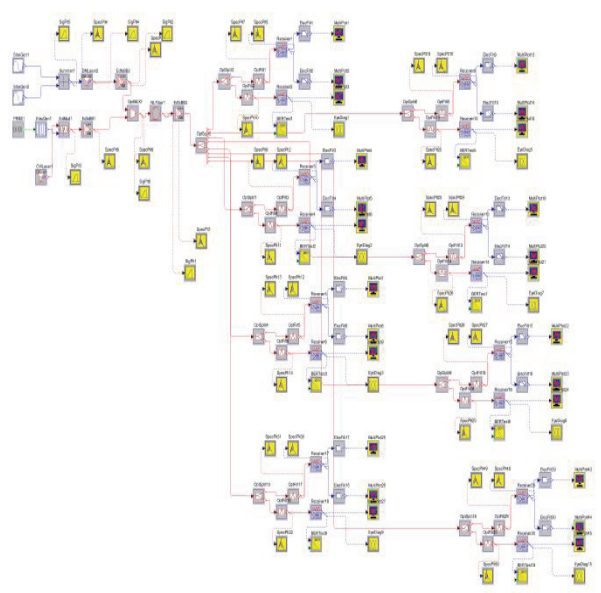

Figure 7. Simulation layout of FTTH using GEPON having 8 users in external modulation. 

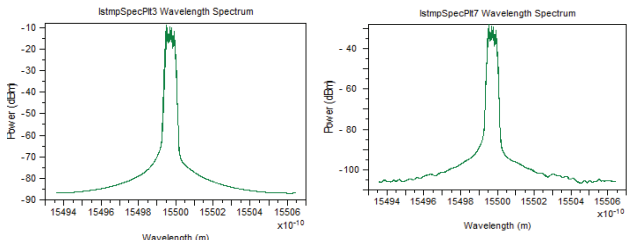

Figure 8. Wavelength spectrum of video signal in transmitter and receiver.
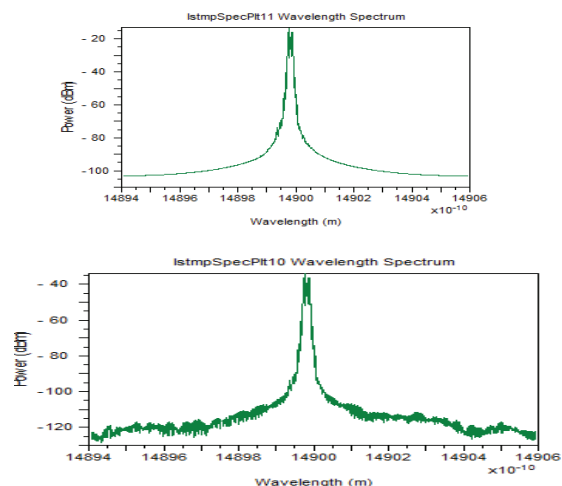

Figure 9. Wavelength spectrum of data signal in transmitter and receiver.
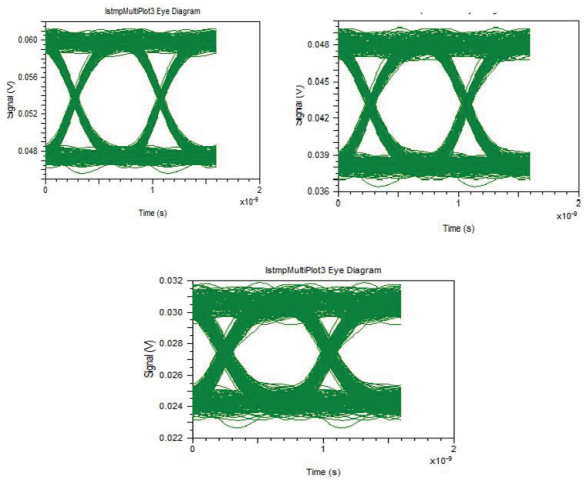

Figure 10. Eye diagram at data receiver with distance $5 \mathrm{~km}$, $10 \mathrm{~km}$ and $20 \mathrm{~km}$.

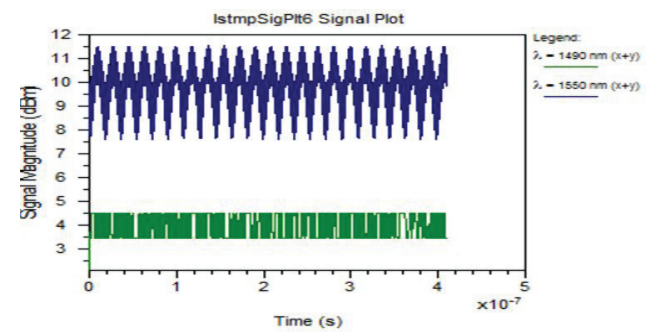

Figure 11. OLT output for video and data signal. the data. So two spectrums are there; one for the video and one for the data. The data is transmitted at the wavelength of $1490 \mathrm{~nm}$ and the video is transmitted at the wavelength of $1550 \mathrm{~nm}$.

Figure 8 and 9 shows the wavelength spectrums of data and video signal in transmitter and receiver. As the signals pass through the fiber, distortion occurs at the receiver side spectum.

At the receiver side, eye diagrams for three different distances $5 \mathrm{~km}, 10 \mathrm{~km}$ and $20 \mathrm{~km}$ are analyzed. From the Figure 10 it is clear that as the distance increases distortion also increases.

Figure 11 shows the wavelength spectrum of the video and data signal at the multiplexer. Both the data is of

Table 1. BER vs distance for different user with direct modulation

\begin{tabular}{llll}
\hline Distance & \multicolumn{1}{c}{$5 \mathrm{~km}$} & \multicolumn{1}{c}{$10 \mathrm{~km}$} & \multicolumn{1}{c}{$20 \mathrm{~km}$} \\
\hline 1 user & $8.5286 \mathrm{e}-140$ & $1.6661 \mathrm{e}-125$ & $1.3842 \mathrm{e}-114$ \\
2 user & $3.9785 \mathrm{e}-134$ & $1.6414 \mathrm{e}-123$ & $1.9829 \mathrm{e}-102$ \\
3 user & $2.3190 \mathrm{e}-126$ & $7.1808 \mathrm{e}-115$ & $1.9876 \mathrm{e}-90$ \\
4 user & $2.1508 \mathrm{e}-120$ & $1.971 \mathrm{e}-105$ & $5.1837 \mathrm{e}-78$ \\
5 user & $5.1788 \mathrm{e}-113$ & $3.9218 \mathrm{e}-96$ & $8.9761 \mathrm{e}-67$ \\
6 user & $3.0325 \mathrm{e}-104$ & $1.2795 \mathrm{e}-87$ & $7.2403 \mathrm{e}-58$ \\
7 user & $6.3298 \mathrm{e}-96$ & $1.5744 \mathrm{e}-79$ & $1.0994 \mathrm{e}-49$ \\
8 user & $1.5136 \mathrm{e}-88$ & $7.8887 \mathrm{e}-72$ & $8.0134 \mathrm{e}-43$ \\
16 user & $1.7028 \mathrm{e}-47$ & $4.3746 \mathrm{e}-34$ & $2.1411 \mathrm{e}-16$ \\
\hline
\end{tabular}

Table 2. BER vs distance for different users with external modulation

\begin{tabular}{lccc}
\hline Distance & $5 \mathrm{~km}$ & $10 \mathrm{~km}$ & $20 \mathrm{~km}$ \\
\hline 1 user & $7.9956 \mathrm{e}-43$ & $2.8734 \mathrm{e}-42$ & $1.4510 \mathrm{e}-42$ \\
2 user & $7.8381 \mathrm{e}-43$ & $2.9196 \mathrm{e}-42$ & $1.6716 \mathrm{e}-42$ \\
3 user & $7.7736 \mathrm{e}-43$ & $3.0127 \mathrm{e}-42$ & $2.0929 \mathrm{e}-42$ \\
4 user & $7.7974 \mathrm{e}-43$ & $3.1460 \mathrm{e}-42$ & $2.9417 \mathrm{e}-42$ \\
5 user & $7.9109 \mathrm{e}-43$ & $3.3205 \mathrm{e}-42$ & $4.8640 \mathrm{e}-42$ \\
6 user & $8.1217 \mathrm{e}-43$ & $3.5408 \mathrm{e}-42$ & $1.0223 \mathrm{e}-41$ \\
7 user & $8.4445 \mathrm{e}-43$ & $3.8153 \mathrm{e}-42$ & $2.4150 \mathrm{e}-41$ \\
8 user & $8.9043 \mathrm{e}-43$ & $4.1579 \mathrm{e}-42$ & $5.5069 \mathrm{e}-41$ \\
16 user & $3.2654 \mathrm{e}-42$ & $2.1108 \mathrm{e}-41$ & $6.9280 \mathrm{e}-39$ \\
\hline
\end{tabular}




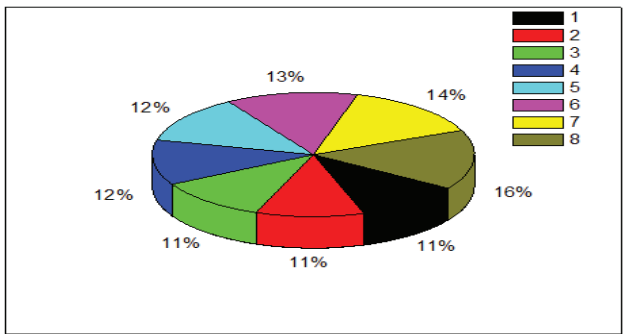

Figure 12. Pie chart of BER vs. Number of users of $10 \mathrm{~km}$ distance with external modulation.

wavelength of $1490 \mathrm{~nm}$ and video is of wavelength 1550 nm can be observed.

The Table 1 and 2 shows that with the direct modulation, the BER is higher for large distances and large number of users, than external modulation. From the Table 2 it is clear that as the distance and users increases the BER also increases. But it is not much affected like direct modulated data (more clear at 16 user).

For the data obtained as in table II the pie chart is plotted (Figure 12). Pie charts show the BER vs. number of users, for $10 \mathrm{~km}$ with external modulation of data. From the chart it is understood that the BER is influenced by the distance and number users.

\section{Conclusion and Future Work}

For optical communication systems, FTTH using PON system design is required to improve transmission performance. GEPON is a perfect combination of Ethernet technology and PON technology. The FTTH using GEPON with direct and external modulation is simulated in the first phase. For the performance evaluation of the system, the BER for different distance and for different users is analyzed. It is observed that as the distance increases the BER also increases. From the analysis, it is evident that as the users increase the BER also increases. At high distance and having large number of users, the BER in the case of external modulation is found to be better than the direct modulation.

\section{References}

1. Kumar S, Sharma S et al. (2012). Optical time division multiplexing system performance and analysis using MZI switching, International Journal of Innovative Technology and Exploring Engineering, vol 1(2), 7-17.

2. Kumar S, Pauria I B et al. (2012). Optical fiber communication system performance using MZI switching, International Journal of Soft Computing and Engineering, vol 2(3), 98-107.

3. Lee C, Sorin W V et al. (2006). Fiber to the home using PON Infrastructure, Journal of Lightwave Technology, vol 24(12), 4568-4583.

4. Nowaka D, and Murphyb J (2012). FTTH: The Overview of Existing Technologies, School of Electronic Engineering, Department of Computer Science, University College Dublin, Dublin, Ireland.

5. Harstead E, and Sharpe R (2012). Alcatel-Lucent, Future fiber-to-the-home bandwidth demands favor time division multiplexing passive optical networks, IEEE Communication Magazine, vol 50(11), 218-223.

6. Gupta M, Malhotra N et al. (2010). Performance analysis of FTTH at $10 \mathrm{Gbit} / \mathrm{s}$ by GEPON architecture, International Journal of Computer Science Issues, vol 7(5), 268-271.

7. Kaler R S (2012). Investigation of FTTH architectures based on passive optical networks, Electronics and Communication Engineering Department, Thapar University.

8. Available From: http://www.rsoftdesign.com/product 